\title{
Rolling Active Control for an Aircraft of Seamless Aeroelastic Wing
}

\author{
Zhengjie Wang* \\ School of Aerospace and Science Engineering, \\ Beijing Institute of Technology, \\ No. 5 Zhong Guan Cun North Street, \\ Hai Dian district, Beijing, 100081, China \\ E-mail: wangzhengjie@bit.edu.cn \\ Daqing Yang and Shijun Guo \\ School of Engineering, Cranfield University, \\ Beds, MK43 0AL, UK \\ E-mail: s.guo@cranfield.ac.uk
}

\begin{abstract}
This paper presents an investigation into the controllability for an aircraft of seamless aeroelastic wing. The research is aimed at the design of control laws for the aircraft rolling by actively operating a pair of an unconventional hingeless flexible leading and trailing control surfaces at different flight speed. The main challenge is how to achieve a specified rolling rate for the aircraft when the control effectiveness drops down and even crosses over the rolling reversal point within the flight envelope. This phenomenon is mainly due to the aeroelastic effect of the large sweptback and highly flexible wing design for weight saving. The investigation shows that control laws varying with the flight speed can be designed to achieve the rolling control target.
\end{abstract}

Keywords: seamless aeroelastic wing; SAW; active rolling control; PID control; optimal control law.

\section{Introduction}

Traditionally, aircraft wing structures are designed to have adequate stiffness and meet other requirements to prevent control reversal and instability phenomena. An obvious penalty to design a stiffer wing is the increase of structural weight. To minimise the weight penalty, research and design effort has been paid to structure optimisation and active control technology. Active aeroelastic wing technology (AAWT) integrates multidisciplinary subjects in structures, aerodynamics and controls together to improve aircraft performance (Andersen et al., 1997). The original goal for applying the AAWT was to achieve the required aircraft performance without paying excessive weight penalty by increasing wing structural stiffness (Diebler and Cumming, 2005). This research program has demonstrated the AAWT feasibility and the potential advantage of using aeroelastic beneficial effect to achieve the goal. The achievement has motivated extensive research in this field. One of the investigations was made to extend the AAWT to developing a rudderless aeroelastic fin for an unmanned aerial vehicle (UAV) design (Allegri et al., 2007). Comparing with large aircraft, a small aircraft, especially a UAV, normally has a the SAW structure has been designed for large weight saving under the strength and aeroelastic stability constraints. Because of the stiffness reduction and a large sweptback wing platform, significant aeroelastic effect and control reversal is inevitable within the flight envelope. The main challenge and solution presented in this paper is how to achieve the aircraft rolling at a specified rate in the flight speed below, crossing over and even beyond the rolling reversal point.

The control system in this paper was designed under the following assumptions: the wing deformation was moderate (Samareh et al., 2007); quasi-steady non-linear model of the wing deformation was used and the small oscillation of the wing corresponding to the unsteady aerodynamics was ignored (Guo, 2007) in the control law design. An integrated control design process for the aircraft rolling in a specified rate was developed. The static aeroelastic effect on the wing deformation and aerodynamic coefficient calculation were considered and integrated into the design process of the control system as shown in Figure1. The investigation shows that control laws varying with the flight speed can be designed to achieve a rolling control target. 
much lower wing load and stress level, hence has more potential of weight saving. However, one of the constraints for significant weight saving is the aircraft aeroelastic limit such as control reversal, which depends upon the wing stiffness. A challenging solution with minimum weight penalty is to maintain the aircraft controllability by applying AAWT in the case of very low control effectiveness and even beyond the control reversal speed.

Doebbler et al. (2005) and Zink et al. (2001) present an integrated trim and structural method for controller design, which applies an optimisation algorithm such as simplex method to calculate the desired deflection of control surface. This design philosophy, in theory, may provide an exact control signal for the aircraft, but difficult to apply to resolve the control problem in practice for its complex optimisation process. Dibley et al. (2005) describes a design process of using wing twist for roll control. Four design regions were defined to establish control strategies across the range of flight speed. The critical roll reversal speed defined a region where control transition from conventional control to wing twists control. The test program is based on an F/A-18 aircraft, which is modified by reducing the wing torsional stiffness. The flight condition demonstrates that the desired roll manoeuvre can be achieved through the use of effective active control.

This paper presents an investigation into the rolling performance of a small aircraft having seamless aeroelastic wing (SAW) at different flight speed. The research is aimed at the design of optimal control laws for the aircraft rolling by actively operating a pair of leading and trailing control surfaces. Unlike the conventional design, the SAW control surfaces are hingeless, flexible and deflected in a seamless curvature shape to obtain high lift to drag ratio. In addition,

Figure 2 A SAW platform and beam sections (see online version for colours)

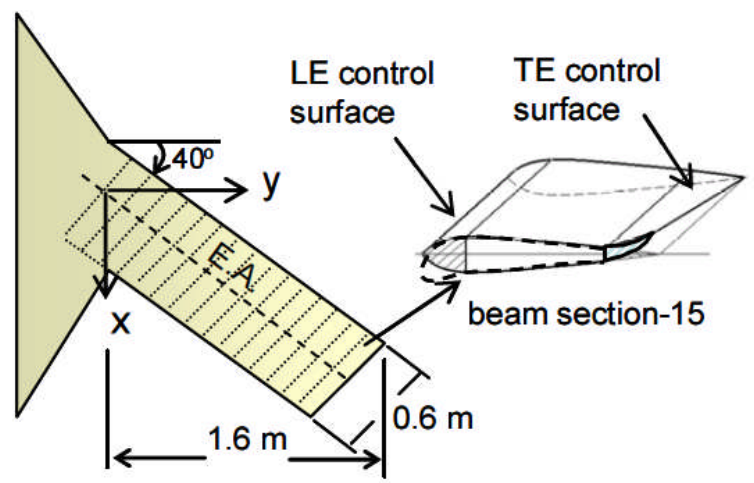

The structural stiffness for each of the single-cell box beam sections can be calculated based on the wing geometry, material properties and laminate lay-ups by employing an analytical method (Armanios and Badir, 1995). In this method, the shear deformation and warping effect are neglected. Subjected to aerodynamic forces acting on the wing, the aeroelastic equations for each of the beam sections can be represented below:

$$
E I_{i} \frac{\partial^{4} h}{\partial y^{4}}+C K_{i} \frac{\partial^{3} \phi}{\partial y^{3}}=\frac{\rho V^{2}}{2} S_{i} C_{L i}\left(\phi, \delta_{\mathrm{TE}}, \delta_{\mathrm{LE}}\right)
$$

Figure 1 SAW UAV integrated design process (see online version for colours)

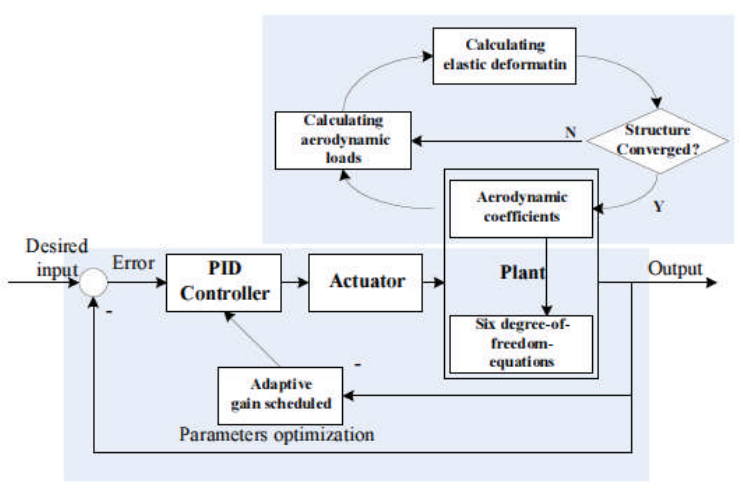

This paper firstly presents the aircraft model including a SAW structural model in Section 2; followed by analysis results for the model in Section 3; the roll control strategy and control law derived for the SAW aircraft in Section 4; the simulation results to track the planned trajectory in Section 5; and conclusions in Section 6.

\section{Aircraft model}

\subsection{Aeroelastic wing structure model}

Since the wing box between the front and rear spars forms the primary structure of a wing and carries the main load, the leading edge (LE) and trailing edge (TE) parts are ignored in modelling of structural properties. For a wing made of composite materials, it can be modelled by a series of span wise single-cell thin-walled beams along the wing box elastic axis (EA) as illustrated in Figure 2.

Under the aerodynamic load, the wing elastic deformation $\left\{d_{1}\right\}$ can be calculated from equation (4). In the next iteration, it will be used to calculate $\left\{A F\left(d_{1}, \delta_{\mathrm{TE}}, \delta_{\mathrm{LE}}\right)\right\}$ and subsequently obtain a revised value for $\left\{d_{2}\right\}$. This aeroelastic calculation continues until the maximum difference $\{\Delta \mathrm{d}\}=\left\{d_{j}\right\}-\left\{d_{j+1}\right\}$ converges to a specified small value. When the convergence criterion is reached, equation (3) is satisfied and the final solution of $\{d\}$ and $\{A F\}$ are obtained. A diverging iteration result indicates an unstable system under the specified control case.

\subsection{Lateral directional linearised flight dynamics model}

The roll motion and the non-linear kinematic equation of an aircraft (Yechout, 2003; Cook, 2007) can be expressed by:

$$
\begin{aligned}
& \dot{P} I_{\mathrm{xx}}+Q R\left(I_{\mathrm{zz}}-I_{\mathrm{yy}}\right)-(\dot{R}+P Q) I_{\mathrm{xz}}=L \\
& P=-\sin \Theta \dot{\Psi}+\dot{\Phi}
\end{aligned}
$$

Assuming small perturbation and neglecting the small derivatives, the linear lateral-direction model becomes:

$$
\dot{p}=L_{\beta} \beta+L_{\mathrm{p}} p+L_{\mathrm{r}} r+\frac{\left(A F_{\mathrm{L}}-A F_{\mathrm{R}}\right) \cdot l_{\mathrm{roll}}}{I_{\mathrm{xx}}}+\frac{I_{\mathrm{xz}}}{I_{\mathrm{zz}}} \dot{r}
$$

where the variable $A F_{L}, A F_{R}$ represent the lifting forces generated by the left and right wing control surfaces, 


$$
\begin{aligned}
& G J_{i} \frac{\partial^{2} \phi}{\partial y^{2}}+C K_{i} \frac{\partial^{3} h}{\partial y^{3}} \\
& =\frac{\rho V^{2}}{2} S_{i} C_{m i}\left(\phi, \delta_{\mathrm{TE}}, \delta_{\mathrm{LE}}\right)+\bar{q} S_{i} C_{L i} e_{i}
\end{aligned}
$$

where $C_{L i}$ and $C_{m i}$ depend on the airfoil shape and the section twist angle $\phi$.

The aerodynamic coefficients for each of the wing sections with deflected LE and TE surfaces are calculated by employing a panel method (Liani et al., 2007). By assembly of the span-wise beam models and 2D aerodynamic forces, the static aeroelastic equation of the wing can be established and written in matrix form:

$$
[K]\{d\}=\left\{A F\left(d, \delta_{\mathrm{TE}}, \delta_{\mathrm{LE}}\right)\right\}
$$

where $\left\{A F\left(d, \delta_{\mathrm{TE}}, \delta_{\mathrm{LE}}\right)\right\}$ includes the lifting force and pitching moment acting on the wing, which are dependent upon $\{d\}$ especially the twist angle, and the LE and TE control surface deflections. For a highly flexible wing of large sweptback angle, a geometrically non-linear and bending-torsion coupled large deformation is expected. To solve the equation in an iterative procedure, equation (3) is expressed in the following form:

$$
[K]\left\{d_{j+1}\right\}=\left\{A F\left(d_{j}, \delta_{\mathrm{TE}}, \delta_{\mathrm{LE}}\right)\right\}
$$

Starting from an initial wing shape $\left\{d_{0}\right\}$ and a control surface input, an initial $\left\{A F\left(d_{0}, \delta_{\mathrm{TE}}, \delta_{\mathrm{LE}}\right)\right\}$ can be calculated.

\section{Aeroelastic wing characteristics}

In this paper, a small aircraft of MTOW $=61 \mathrm{~kg}$ is investigated. The aircraft has a large sweptback SAW as illustrated in Figure 2. NACA0015 and NACA0006 airfoil are chosen for the wing root and tip section respectively. The wing box is made of composite materials and modelled by using 15 span wise single-cell thin-walled beams along the EA as shown in Figure 2. The structural stiffness of the 15 beam sections has been calculated using the method described in Section 2.1 and listed in Table 1. The LE and TE control surfaces are positioned in the 15 th wing section of length $0.09 \mathrm{~m}$ in span wise. They are activated and deflected by internal actuators from $30 \%$ and $60 \%$ chord respectively.

Table 1 Stiffness details of the thin-walled wing box sections for the beam model

\begin{tabular}{lcccc}
\hline Section no. & $I$ & 2 & 3 & 4 \\
\hline $\mathrm{EI} \times 10^{3}$ & 37.6 & 29.8 & 25.6 & 22.9 \\
$\mathrm{GJ} \times 10^{3}$ & 16.4 & 12.6 & 10.7 & 9.75 \\
$\mathrm{CK} \times 10^{3}$ & -4.67 & -3.58 & -3.06 & -2.78 \\
\hline Section no. & 5 & 6 & 7 & 8 \\
\hline $\mathrm{EI} \times 10^{3}$ & 20.4 & 18 & 15.8 & 13.8 \\
$\mathrm{GJ} \times 10^{3}$ & 8.8 & 7.89 & 7.06 & 6.24 \\
$\mathrm{CK} \times 10^{3}$ & -2.51 & -2.25 & -2.01 & -1.77 \\
\hline Section no. & 9 & 10 & 11 & 12 \\
\hline EI $\times 10^{3}$ & 12 & 10.3 & 8.67 & 7.27
\end{tabular}

respectively, which can be obtained in equation (4); lateral-directional stability parameters associated with equation (7) are expressed as:

$$
\begin{aligned}
& L_{\beta}=\frac{\bar{q} S b}{I_{\mathrm{xx}}} C_{l \beta} \\
& L_{\mathrm{p}}=\frac{\bar{q} S b^{2}}{2 I_{\mathrm{xx}} U_{1}} C_{l \mathrm{p}} \\
& L_{\mathrm{r}}=\frac{\bar{q} S b^{2}}{2 I_{\mathrm{xx}} U_{1}} C_{l \mathrm{r}} \\
& \bar{q}=\frac{\rho V^{2}}{2}
\end{aligned}
$$

In an attempt to simplify the study and focus on the roll mode by the wing control only, the variables $\beta, r$ and $\dot{r}$ are temporarily removed from equation (7), thereby reducing it to:

$$
\dot{p}=L_{\mathrm{p}} p+\frac{\left(A F_{\mathrm{L}}-A F_{\mathrm{R}}\right) \cdot I_{\text {roll }}}{I_{\mathrm{xx}}}
$$

As mentioned in equation (3), the lifting forces $A F_{\mathrm{L}}$ and $A F_{\mathrm{R}}$ are dependent upon the $\mathrm{LE}$ and TE control surface deflections. The roll mode will be generated by the deflection the LE and TE control surfaces. The roll mode can be characterised by studying the aircraft response to the TE or LE deflection.

reduced to zero. This is because the wing camber effect on the lift due to TE deflection is cancelled by the wing aeroelastic twist. At this speed, the wing lift is not sensitive to the TE deflection.

Figure 3 Lifts against TE deflection at different speed (see online version for colours)

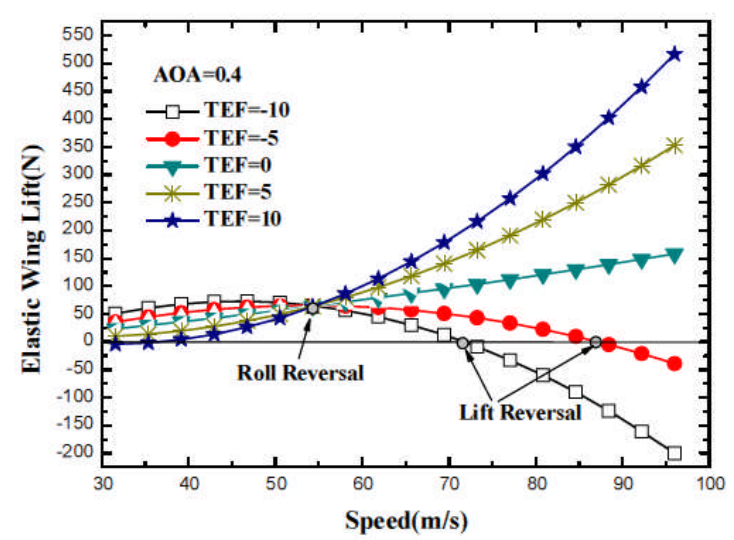

Figure 4 shows the lift versus flight speed at different TE deflections. It shows that at the critical speed, the left and right wing generates the same lift no matter how their TE control surfaces are deflected, which will make the rolling moment equal to zero. This critical speed is therefore called the roll reversal point, which is different from the lift reversal point. 


\begin{tabular}{lcccc}
$\mathrm{GJ} \times 10^{3}$ & 5.49 & 4.75 & 4.1 & 3.49 \\
$\mathrm{CK} \times 10^{3}$ & -1.56 & -1.36 & -1.17 & -0.991 \\
\hline Section no. & 13 & 14 & 15 \\
\hline $\mathrm{EI} \times 10^{3}$ & 5.98 & 4.83 & 2.48 \\
$\mathrm{GJ} \times 10^{3}$ & 2.92 & 2.4 & 1.15 \\
$\mathrm{CK} \times 10^{3}$ & -0.83 & -0.683 & -0.327 \\
\hline
\end{tabular}

Because of the large flexibility and sweptback of the SAW structure, control reversal due to negative aeroelastic effect occurs within the flight envelope. In such case, it is a challenge for the control system design to achieve a specified rolling motion by operating the TE, and if necessary, the LE control surfaces. In the example, the SAW has an initial angle of attack (AoA) $0.4^{\circ}$.

Figure 3 shows the aerodynamic lift of one wing versus TE deflection angle varying from $-10^{\circ}$ to $+10^{\circ}$ at a flight speed range from $30 \mathrm{~m} / \mathrm{s}$ to $70 \mathrm{~m} / \mathrm{s}$.

It shows that the lifting force generated by deflecting the TE control surface varies with the speed. At a speed below $54 \mathrm{~m} / \mathrm{s}$ when the wing twist is small, a negative (down) deflection of the TE control surface produces a lift increase. At a higher speed beyond $54 \mathrm{~m} / \mathrm{s}$, however, a negative TE deflection causes a negative wing twist due to aeroelastic effect, which effectively reduces the angle of attack and decreases the lift unless the TE deflection goes to the opposite positive (up) direction. It is also noted that at the critical speed of $54 \mathrm{~m} / \mathrm{s}$, the TE control effectiveness is

the lower and higher speed regions, the aircraft roll motion can be controlled by only the TE deflection. In the lower speed region, the aerodynamic forces and aircraft rolling moment is produced by the wing camber due to the TE deflection; while in the upper region, it is primarily caused by the wing twist due to aeroelastic effect. It also shows that, in this higher speed region, the LE is capable of generating wing twist, which produces rolling moment. Thus, in this higher speed region, the other control strategy is to use the conventional TE combining with the LE by using the LE to counter the adverse twist created by the TE.

Figure 5 Rolling moment versus speed for TE and LE deflections (see online version for colours)

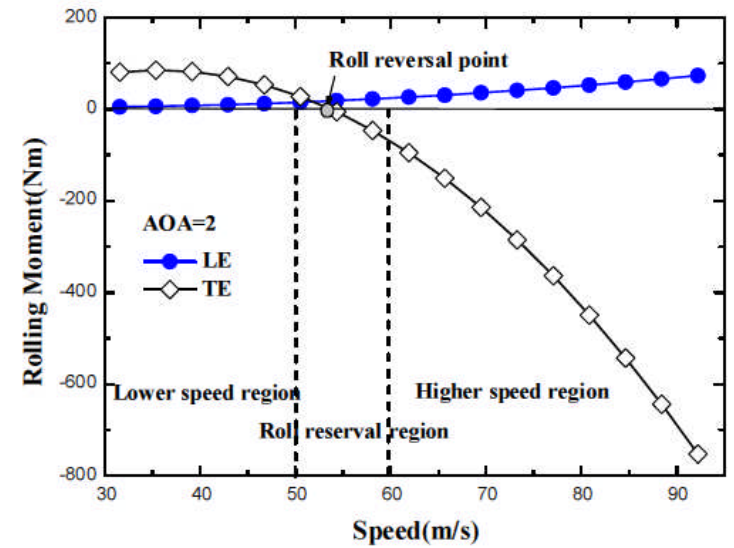

Figure 4 Lift against speed at different TE deflection (see online version for colours)

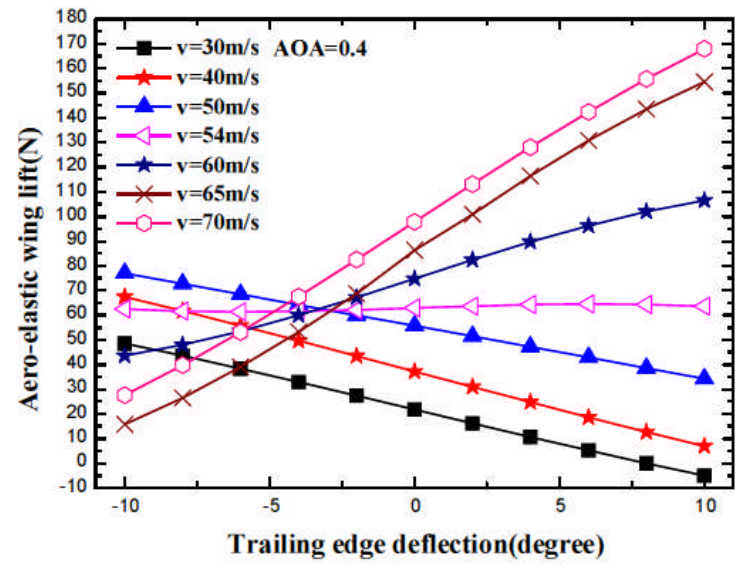

As shown in Figure 4, it is important to realise that the relationship between the deflection angle of control surface $\delta$ and the lifting force $A F$ is approximately linear. Again, the lifting force in equation (4) may be written:

$$
A F\left(d, \delta_{\mathrm{TE}}, \delta_{\mathrm{LE}}\right)=f_{\delta_{\mathrm{IE}}} \cdot \delta_{\mathrm{LE}}+f_{\delta_{\mathrm{TE}}} \cdot \delta_{\mathrm{TE}}
$$

Figure 5 shows the roll reversal point divides the speed range into three regions, which are the lower speed region, the roll reversal region and above reversal speed region. In

\section{Controller design}

\subsection{Control law architecture}

For the rolling control of the SAW aircraft discussed earlier in this paper, flight speed is a very important parameter, which may require different control strategy. Figure 7 shows the control architecture for the aircraft, in which $\Phi_{\mathrm{i}}$ and $p_{\mathrm{i}}$ are the desired roll control reference signal. The rolling rate and rolling angle measured from the gyro sensors are feedback to the controller. In the control process, a flight state boundary is designed to separate different control strategy in different flight speed. A variable gain PID-type control law is employed for the aircraft rolling control. This makes the aircraft rolling meet the commanded requirement (Guo et al., 2006; Houda, 2007).

Figure 7 A rolling control architecture for SAW aircraft

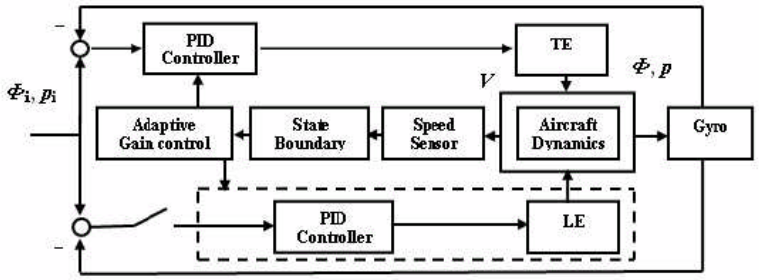

\subsection{Control strategy design}


Figure 6 shows the rolling moment versus flight speed with a focus on the roll reversal region. When only the TE is deflected, the rolling moment indicated by curve- 1 becomes zero at the critical speed. When a combination of the TE and LE control surface deflection is introduced, as shown on the curve- 2 to curve- 5 in Figure 6, the rolling moment value is shifted away from zero at the critical speed. In other words, the critical speed is shifted. The control strategy, in this region, should be to favour the use of optimal combination between the TE and LE.

Figure 6 Rolling moment at reversal speed in a mixture of TE and LE (see online version for colours)

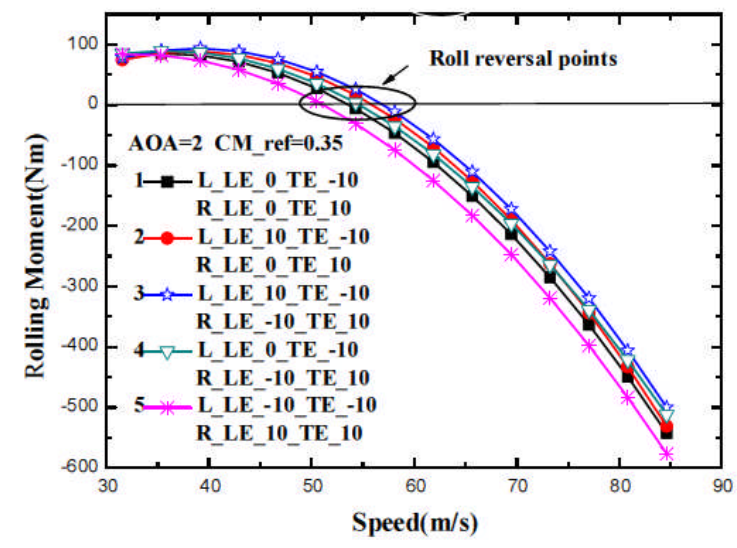

control surface was deflected downward (negative) to gain an increasing lift and positive rolling moment (clockwise). Beyond the reversal speed, the left wing TE deflection was changed from negative to positive (upward) to keep the lift and rolling moment positive. In the same time, the right wing TE deflects in the opposite direction. Figure 8(b) shows that not all the rolling rate reaches $2 \mathrm{deg} / \mathrm{s}$. The roll performance is especially poor when the flight speed is close to the reversal point. An optimal control law therefore needs to be designed.

Figure 8 (a) Time histories of the TE deflections at the different speeds (b) roll rate tracking performance (see online version for colours)

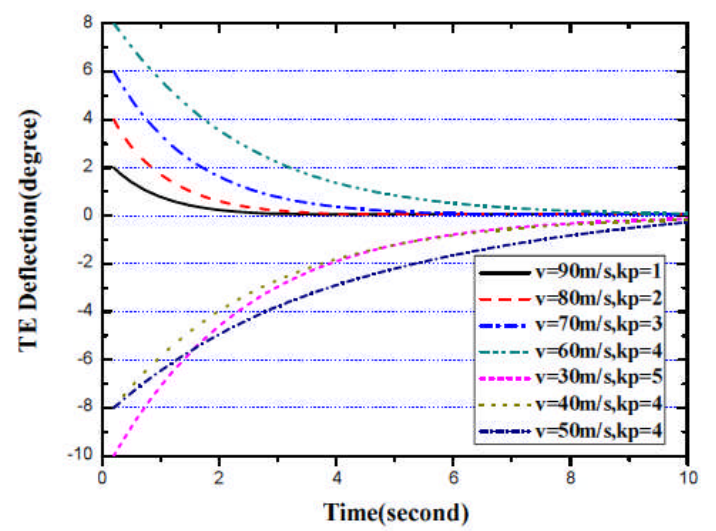

(a)
By using the power of Laplace transforms and the analysis result in equation (9), the transfer-function relating the system output $P(s)$ and $\Phi(s)$ to the control input $\delta_{\mathrm{dTE}}(s)$ are given by

$$
\begin{aligned}
& \frac{p(s)}{\delta_{\mathrm{dTE}}(s)}=\frac{L_{\delta_{\mathrm{dTE}}}}{\left(s-L_{\mathrm{p}}\right)} \\
& \frac{\Phi(s)}{\delta_{\mathrm{dTE}}(s)}=\frac{L_{\delta_{\mathrm{dTE}}}}{s\left(s-L_{\mathrm{p}}\right)}
\end{aligned}
$$

where

$$
\begin{aligned}
& \delta_{\mathrm{dTE}}=\delta_{\mathrm{TE}_{\mathrm{Left}}}-\delta_{\mathrm{TE}_{\text {Right }}} \\
& \delta_{\mathrm{dLE}}=\delta_{\mathrm{LE}_{\text {left }}}-\delta_{\mathrm{LE}_{\text {Right }}} \\
& L_{\delta_{\text {dec }}}=\frac{\left(f_{\delta_{\mathrm{TE}_{\text {left }}}}-f_{\delta_{\mathrm{TE}_{\mathrm{right}}}}\right) \cdot l_{\text {roll }}}{I_{\mathrm{xx}}}
\end{aligned}
$$

Figure 8 shows TE deflection and the responses of the P-type control loop for a roll control at flight speeds from $30 \mathrm{~m} / \mathrm{s}$ to $90 \mathrm{~m} / \mathrm{s}$. In this case, the expected achievable roll rate is $2 \mathrm{deg} / \mathrm{s}$, indicated by the solid straight line in Figure 8(b). As described earlier, when the flight speed crosses over the rolling moment reversal point, the TE control surface deflection changed direction in order to maintain the positive rolling moment. For example, at a flight speed below the reversal value, the left wing TE

interface form, which employs a gradient-based optimisation algorithm to find an optimal solution towards the control target within the upper and lower boundary.

Figure 9 Simulink optimisation design block (see online version for colours)

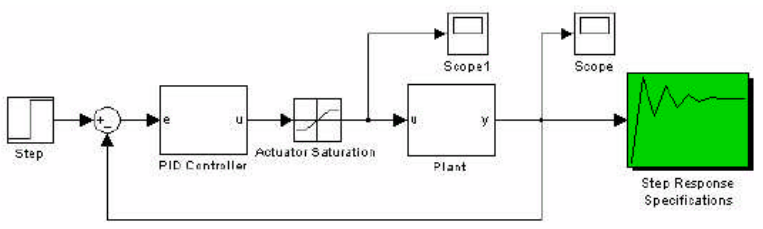

Figure 10 (a) Rolling rate tracking performance (b) time histories of the TE deflections (see online version for colours)

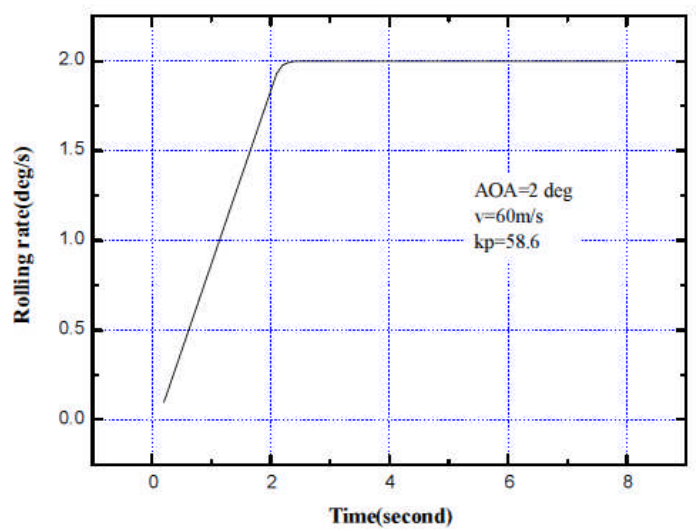

(a) 


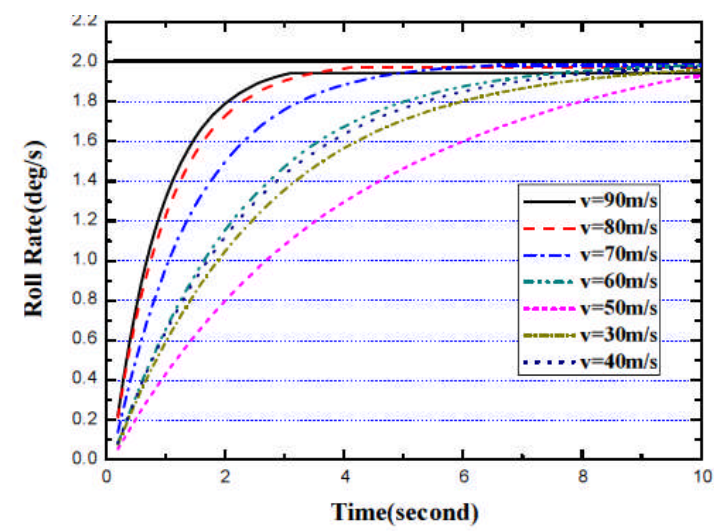

(b)

\subsubsection{PID optimisation design}

Matlab/Simulink response optimisation toolbox is employed to design the PID-type controller as shown in Figure 9. Although saturation in the control loop should be considered in the practical actuator working range, an optimum solution still can be obtained from the Simulink response optimisation signal block process. A process for optimising control law parameters can be obtained from the graphic

\subsubsection{Combination of TE and LE control}

A similar design process is applied in evaluating the parameters at the rolling reversal speed of $54 \mathrm{~m} / \mathrm{s}$. At this particular speed, a combination of the TE and LE control surfaces for both left and right wing as illustrated in Figure 11 can be selected to enhance the rolling moment.

Figure 11 A combination of the TE and LE deflection

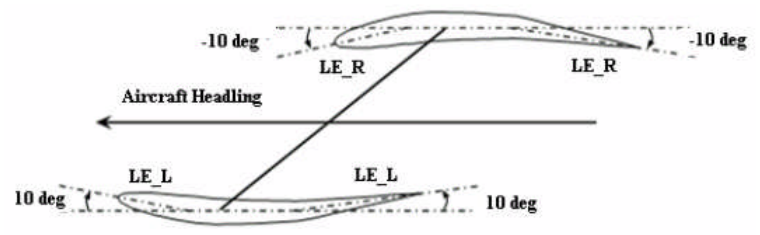

Figure 12 Time histories of, (a) roll attitude (b) control surfaces deflection (see online version for colours)

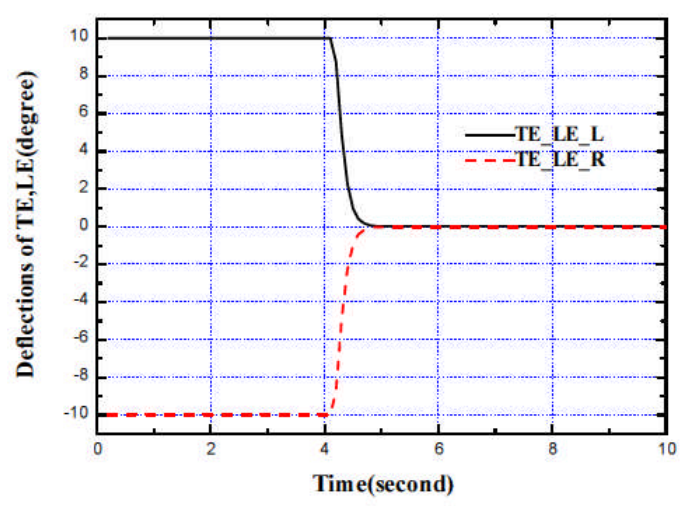

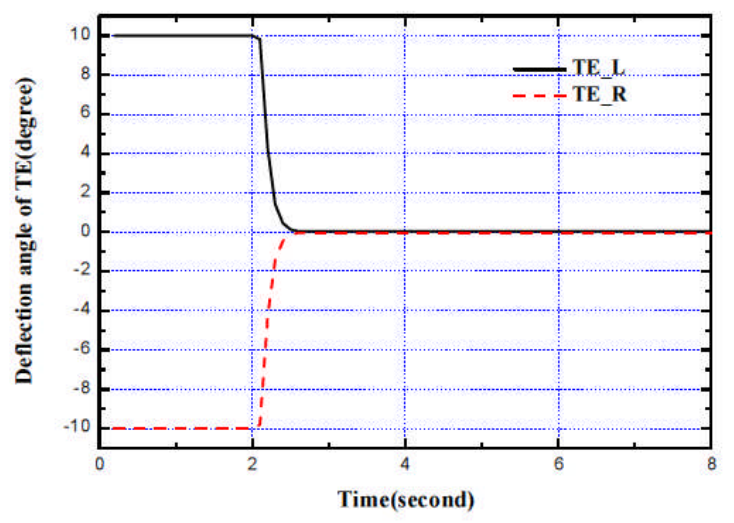

(b)

To test the designed proportional parameters using the above linear model, the simple transfer function was replaced by a differential equation model. The simulation result shown in Figure 10(a) indicates that the P-type algorithm and the optimised parameters are satisfactory in a realistic non-linear situation. In this particular case, however, a maximum TE deflection up to $\pm 10^{\circ}$ is required to meet the target as shown in Figure 10(b).

\subsubsection{Variable-gains optimisation PID control law}

Using the Simulink response optimisation toolbox, the PID-type roll rate control law can be obtained and the optimised results as listed in Table 2.

Table 2 Optimisation PID control law parameters

\begin{tabular}{lcccc}
\hline Flight conditions & \multicolumn{4}{c}{ Control surface deflection trajectory } \\
\hline $\mathrm{AOA}=2^{\circ}$ & LE_L & TE_L & LE_R & TE_R \\
$\mathrm{V}=30 \sim 40 \mathrm{~m} / \mathrm{s}$ & 0 & Down & 0 & $\mathrm{Up}$ \\
$\mathrm{V}=50 \sim 54 \mathrm{~m} / \mathrm{s}$ & $\mathrm{Up}$ & Down & Down & $\mathrm{Up}$ \\
$\mathrm{V}=54-60 \mathrm{~m} / \mathrm{s}$ & $\mathrm{Up}$ & $\mathrm{Up}$ & Down & Down \\
$\mathrm{V}=60-90 \mathrm{~m} / \mathrm{s}$ & 0 & $\mathrm{Up}$ & 0 & Down \\
\hline Flight conditions & Roll rate control & Roll angle control \\
& target & target \\
\hline $\mathrm{AOA}=2^{\circ}$ & Output settling & Rising time $<3 \mathrm{~s} ;$ \\
& time $<3 \mathrm{~s}$ & output settling time \\
& & $<6 \mathrm{~s} ;$ overshoot \\
$\mathrm{V}=30 \sim 40 \mathrm{~m} / \mathrm{s}$ & $k_{\mathrm{p}}=24$ & $k_{\mathrm{p}}=12, k_{\mathrm{d}}=23$ \\
$\mathrm{~V}=50 \sim 54 \mathrm{~m} / \mathrm{s}$ & $k_{\mathrm{p}}=63$ & $k_{\mathrm{p}}=12, k_{\mathrm{d}}=23$ \\
$\mathrm{~V}=54-60 \mathrm{~m} / \mathrm{s}$ & & \\
& & $k_{p}=8.92 e^{\frac{-V}{3.16}}-0.1$ \\
$\mathrm{~V}=60-90 \mathrm{~m} / \mathrm{s}$ & $5.4772 \mathrm{~V}+237.68$ & $k_{d}=1.25 e^{\frac{-V}{4.28}}+1.28$ \\
& &
\end{tabular}

\section{Simulation}


(a)

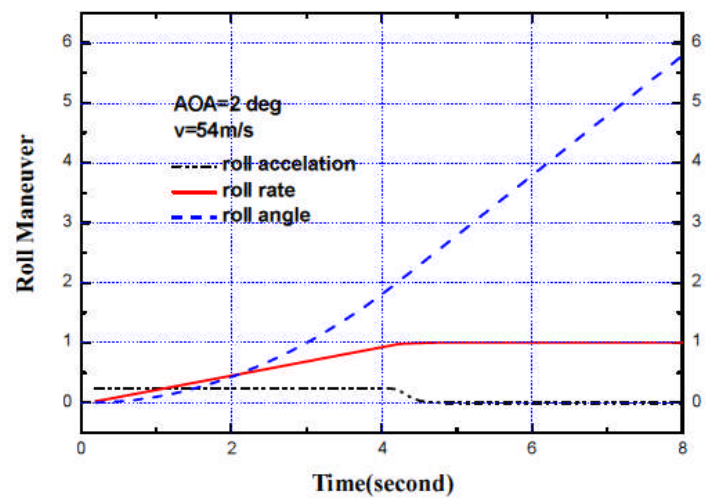

(b)

Simulation results presented in Figure 12(a) shows that a stable roll rate up to $1 \mathrm{deg} / \mathrm{s}$ can be achieved by applying the optimised P-type control method. Even though the achievable roll rate is only half of that in other speed regions, the TE and LE deflection have to keep at their saturation state of $\pm 10^{\circ}$ for four seconds as shown in Figure 12(b). This shows that the control for rolling reversal point is in deed a challenge.

Figure 13 Flight speed trajectory (see online version for colours)

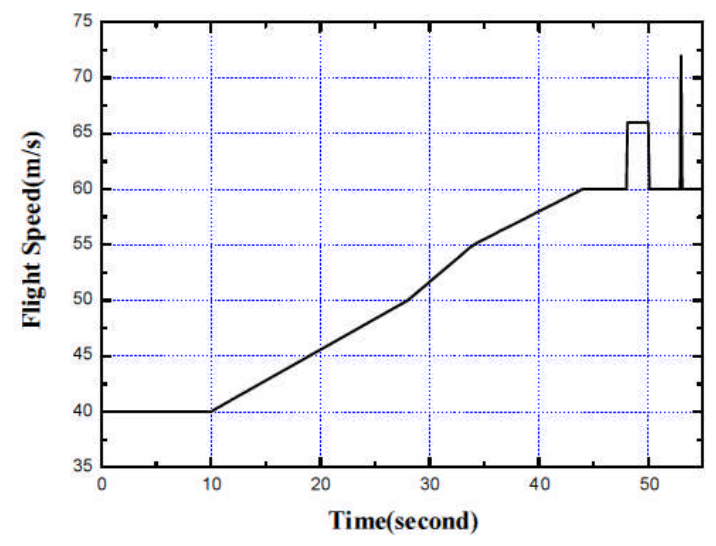

Figure 14 (a) Rolling rate tracking (b) time histories of the roll angle (c) time histories of the TE and LE deflection (see online version for colours)

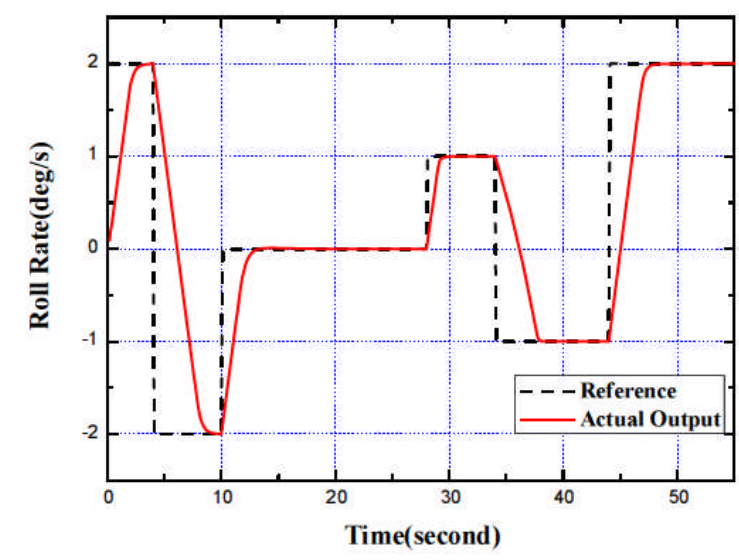

(a)
In the simulation, the whole flight speed range is divided into four stages within a time scale as shown in Figure 13. In the first stage up to $40 \mathrm{~m} / \mathrm{s}$, the speed remains constant. The second and third stages are connected from $40 \mathrm{~m} / \mathrm{s}$ up to $60 \mathrm{~m} / \mathrm{s}$ with different accelerations. In the final speed stage of $60 \mathrm{~m} / \mathrm{s}$, two types of wind turbulence are considered. One is a constant turbulence, which lasts about 20 seconds and makes the flight speed change to $65 \mathrm{~m} / \mathrm{s}$; another is a random wind turbulence, which abruptly makes the flight speed change up to $72 \mathrm{~m} / \mathrm{s}$. The aim of considering the above flight trajectory is to test the adaption performance of the designed control law (Kim et al., 2007).

The small SAW aircraft should follow the flight speed trajectory. In different speed stage, it should trace the reference roll rate indicated by the dotted line shown in Figure 14(a). In the second speed stage, for example, the reference roll rate and roll angle are both zero, which indicates that the aircraft accelerates from $40 \mathrm{~m} / \mathrm{s}$ to $50 \mathrm{~m} / \mathrm{s}$ without rolling. The solid line shown in Figures 14(a) and 17(b) indicates the actual roll rate and roll angle. From the figures, we can see that the output settling time meets the control target. Figure 14(c) shows the time histories of the TE and LE deflection over the whole speed range.

Figure 14 (a) Rolling rate tracking (b) time histories of the roll angle (c) time histories of the TE and LE deflection (continued) (see online version for colours)

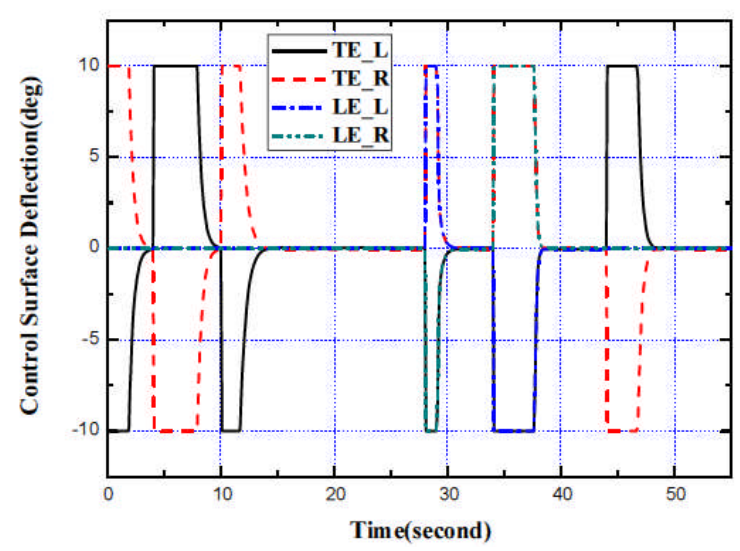

(c)

\section{Conclusions}

A PID-type control law for the rolling of a lightweight and flexible SAW aircraft has been designed. The aeroelastic effect of the wing structure on the aircraft roll control has been investigated and modelled. To improve the control performance when considering the aeroelastic negative effect, the control law is designed by an optimised PID algorithm. A roll motion control trajectory has also been simulated to study the control stability of the control system. The flight simulation results demonstrate that an effective roll control can be achieved for the SAW aircraft considering the effect of non-linear aeroelastic deformation. 


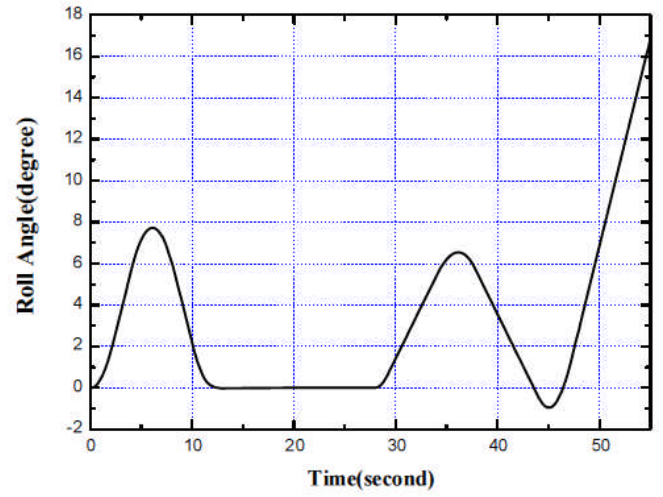

(b)

Samareh, J.A., Chwalowsk, P., Horta, L.G. and Piatak, D.J. (2007) 'Integrated aerodynamic/structural/dynamic analysis of aircraft with large shape changes', 48th AIAA/ASME/ASCE/AHS/ASC Structure, Structural Dynamics, and Materials Conference, No. AIAA-2007-2346, Honolulu, Hawaii.

Yechout, T.R. (2003) 'Introduction to aircraft flight mechanics', American Institute of Aeronautics and Astronautics, Inc., pp.239-296.

Zink, P.S., Mavris, D.N. and Raveh, D.E. (2001) 'Maneuver trim optimization techniques for active aeroelastic wings', Journal of Aircraft, Vol. 38, No. 6, pp.1139-1146.

\section{Nomenclature}

\section{References}

Allegri, G., Guo, S. and Trappani, M. (2007) 'On the design of an aeroservoelastic fin for a flight demonstrator', International Forum on Aeroelasticity and Structural Dynamics, Stockholm, Sweden, pp.18-20.

Andersen, G., Forster, E. and Kolonay, R. (1997) 'Multiple control surface utilization in active aeroelastic wing technology', Journal of Aircraft, Vol. 34, No. 4, pp.552-531.

Armanios, E.A. and Badir, A.M. (1995) 'Free vibration analysis of anisotropic thin walled closed-cross-section beams', AIAA Journal, Vol. 33, pp. 1905-1910.

Cook, M.V. (2007) Flight Dynamics Principles, Butterworth-Heinemann, pp.174-206.

Dibley, R.P., Allen, M.J. and Clarke, R. (2005) 'Development and testing of control laws for the active aeroelastic wing program', AIAA Atmospheric Flight Mechanics Conference and Exhibit, No. AIAA-2005-6314, San Francisco, California.

Diebler, C.G. and Cumming, S.B. (2005) 'Active aeroelastic wing aerodynamic model development and validation for a modified F/A-18A airplane', NASA TM-2005-213668.

Doebbler, J., Tandale, M.D. and Valsedk, J. (2005) 'Improved adaptive-reinforcement learning control for morphing unmanned air vehicles', AIAA Guidance, Navigation, and Control Conference and Exhibit, No. AIAA-2005-7159, Arlington, Virgina.

Guo, G., Ma, Z. and Qiao, J. (2006) 'State-PID feedback control with application to a robot vibration absorber', International Journal of Modeling, Identification and Control, Vol. 1, No. 1 , pp.38-43.

Guo, S. (2007) 'Aeroelastic optimisation of an aerobatic aircraft wing structure', Aerospace Science \& Technology, Vol. 11, pp.396-404.

Houda, B.J.D. (2007) 'On the PID control of systems with large delays', International Journal of Modeling, Identification and Control, Vol. 2, No. 1, pp.66-71.

Kim, B.M., Choi, K. and Kim, B. (2007) 'Trajectory tracking controller design using neural networks for rotor UAV', AIAA Guidance, Navigation, and Control Conference and Exhibit, No. AIAA-2007-6460, Hilton head, South Carolina.

Liani, E., Guo, S. and Allegri, A. (2007) 'Potential-flow-based aerodynamic analysis and test of a flapping wing', 37th AIAA Fluid Dynamics Conference. No. AIAA-2007-4068, Florida.

$\begin{array}{ll}A F & \text { Aerodynamic force vector } \\ b & \text { Wing span } \\ d & \text { Wing deformation vector } \\ C_{L i} & \text { Lift coefficient } \\ C_{m} & \text { Pitching moment coefficient } \\ C K & \text { Bending-torsion coupling stiffness of the ith beam } \\ C_{l \beta} & \text { Rolling moment coefficients due to the angle of } \\ C_{l p} & \text { sideslip } \\ C_{l r} & \text { Rolling moment coefficient due to rolling rate } \\ E I & \text { Rolling moment coefficient due to yaw rate } \\ e & \text { Bending stiffness of the ith wing beam } \\ f_{\delta L E} & \text { Distance between the reference point of } C_{m} \text { and the } \\ f_{\delta \mathrm{TE}} & \text { Lifting centre along the beam } \\ I_{\mathrm{xx}} & \text { Lifting force coefficients due to TE deflection } \\ I_{\mathrm{yy}} & \text { Moment of inertia about the x axis } \\ I_{z z} & \text { Moment of inertia about the y axis } \\ I_{\mathrm{xz}} & \text { Moments of inertia about the } \mathrm{z} \text { axis } \\ G J & \text { Product of inertia in x-z plane of the aircraft } \\ h & \text { Transverse displacement of the } i \text { th wing beam }\end{array}$

Product of inertia about $o x$ and $o z$ axes Stiffness matrix of the whole wing Rolling moment

Distance between the reference point of $A F$ and the body $\mathrm{x}$ axis

Roll angle

Pitch angle

Heading angle

Roll rate

Pitching rate 
$p \quad$ Perturbed value of the roll rate

$r \quad$ Perturbed value of the yaw rate

$S \quad$ Wing area

$U_{1} \quad$ Axial component of steady equilibrium velocity

$V \quad$ Total velocity

$\rho \quad$ Air density

$\delta_{\mathrm{TE}} \quad$ TE deflection angle

$\delta_{\mathrm{LE}} \quad$ LE deflection angle

$\Phi \quad$ Twist angle of the ith wing beam

$\beta \quad$ Sideslip angle 